\title{
Pemberdayaan masyarakat Desa Sri Agung untuk meningkatkan ketahanan pangan dengan introduksi padi hitam di pekarangan
}

Made Deviani Duaja*, Buhaira, Nelyati, dan Elis Kartika

Universitas Jambi

*madedevianiduaja@yahoo.com

\begin{abstract}
Now rice can be planted in the yard, using polybags and SRI Method (one seed per pot). Liquid organic fertilizer based on local microorganism (LOM) which is obtained by fermentation livestock urine and extract of golden snail. This extract is used as biodecomposer to ferment livestock waste into solid and liquid fertilizer. The fertilizer is used for black rice plant in polybag. This technology was applied in Sri Agung village from Sido Rukun and Sido Mukti area, specially for womens from several RT and for agriculture womens association that are active in the utilization of yard. The target is to increase the yield of the yard, previously no rice crops, now exist, at least each pot produced $500 \mathrm{~g}$ of dry black rice, 100 liters of liquid organic fertilizer per month and $50 \mathrm{~kg}$ of solid fertilizer per two months. The result showed, the level of PKK participation when mentoring is high because from 50 people, 40 people are present in every activity. Evaluation showed there are high farmer participation in land preparation and demonstration of RINMAS technology and low level farmers participation in implementation SRI method. It is recommended to planting rice on the yard.
\end{abstract}

Abstrak Padi hitam metode SRI di pot adalah cara menanam padi satu biji per
pot. Teknologi ini menggunakan pupuk organik cair dari MOL urin dan
Keongmas (MOL RINMAS). MOL yang sudah difermentasi digunakan sebagai
dekomposer untuk membuat pupuk padat yang akan digunakan sebagai media
untuk menanaman padi hitam secara SRI di pot. Pupuk cair digunakan sebagai
pupuk daun padi. Teknologi ini diterapkan di Desa Sri Agung, pada ibu PKK
Dusun Sido Rukun dan Dusun Sido Mukti. Evaluasi didasarkan pada keaktifan
ibu PKK sejak penyuluhan, demplot, pendampingan dan perawatan tanaman dan
apakah tetap membuat POC berbasis MOL Rinmas (urin+keongmas) dan apakah
tetap digunakan. Targetnya, peningkatan hasil pekarangan minimal setiap
anggota yang menanam dihasilkan 500 g/pot gabah kering, pupuk cair 100 liter
per bulan dan padat 50 kg per dua bulan. Hasil menunjukkan tingkat partisipasi
petani dalam penyuluhan tergolong tinggi karena dari 50 orang, 40 orang hadir
dalam setiap penyuluhan, pembuatan rinmas tergolong tinggi, penyiapan benih
secara SRI tergolong rendah, pengolahan tanah tergolong tinggi, penanaman
tergolong sedang, aplikasi pupuk tergolong sedang, terdapat peningkatan hasil
pekarangan dibandingkan sebelumnya. Direkomendasikan untuk menerapkan
padi hitam berbasis Teknologi RINMAS pada budidaya tanaman di pekarangan.

Keywords: MOL; urine; golden snail; yard; liquid organic fertilizer

\section{○ OPEN ACCESS}

Citation: Duaja, M. D., Buhaira, Nelyati, dan E. Kartika. 2018. Pemberdayaan Masyarakat Desa Sri Agung untuk Meningkatkan Ketahanan Pangan dengan Introduksi Padi Hitam di Pekarangan. Riau Journal of Empowerment 1(1): 37-43

https://doi.org/10.31258/raje.1.1.5

Received: 2018-05-18, Revised: 2018-06-24, Accepted: 2018-07-31

Language: Bahasa Indonesia (id)

Funding: Kegiatan pengabdian ini didanai dari Hibah Pengabdian pada Masyarakat Skim Ipteks bagi Masyarakat oleh Kementerian Riset, Teknologi dan Pendidikan Tinggi

C 2018 Duaja et al. The article by Author(s) is licensed under a Creative Commons Attribution 4.0 International License. This license permits unrestricted use, distribution, and reproduction in any medium, provided the original author and source are credited. 


\section{PENDAHULUAN}

Kabupaten Tanjung Jabung Barat adalah salah satu kabupaten yang relatif muda di Provinsi Jambi. Secara umum, tampak pembangunan belum merata, hal ini terlihat dari perkembangan yang pesat di pusat kota, namun, desa yang jauh dari pusat kota ini tampak masih banyaknya rumah tangga miskin, yaitu 28 persen dari jumlah penduduk [2]. Batang Asam adalah salah satu kecamatan di kabupaten ini yang terus berkembang, pada awalnya hanya memiliki 5 desa dan 1 kelurahan, sekarang menjadi 10 desa dan 1 kelurahan. Masyarakat di kecamatan ini terdiri atas beberapa suku, terutama suku Jawa, Melayu dan Bugis. Pembangunan kecamatan Batang Asam diarahkan pada peningkatan produksi produk pertanian untuk mendukung ketahanan pangan rumah tangga. Desa Sri Agung adalah salah satu desa di Kecamatan ini yang petaninya sangat respon teknologi. Pendampingan terhadap keluarga sebagai unit terkecil sudah di lakukan oleh penyuluh dan kader Pos Daya terutama di bidang pemanfaatan pekarangan sebagai lumbung pangan. Desa ini mempunyai beberapa Kelompok Wanita Tani (KWT) yang merupakan gabungan dari beberapa kelompok PKK terutama yang aktif bekerja di bidang pertanian misalnya sebagai buruh tanam, pemupukan, penyiangan dan pemberantasan hama. Kelompok PKK sudah aktif memanfaatkan pekarangan dan sudah membentuk Dasa Wisma berdasarkan jenis tanaman yang di tanam, hal ini untuk saling tukar informasi tentang budidaya tanaman dan kendalanya.

Pada umumnya pekarangan sudah dimanfaatkan untuk TOGA, warung hidup untuk keperluan sehari-hari dan dijual, namun belum maksimal. Keadaan ini disebabkan pendidikan ibu-ibu yang rendah sehingga kemampuan untuk membantu pendapatan keluarga juga sangat rendah, hal ini berhubungan erat dengan kondisi ekonomi yang lemah. Ketergantungan pada pupuk anorganik tampak dari hasil pekarangan yang rendah, dan hanya dapat dijual di warung dan pasar-pasar mingguan satu kali. Rendahnya karena pemupukan tidak optimal, pada waktu harga pupuk mahal tanaman tidak di pupuk karena pupuk bergantung pada pupuk yang disimpan untuk tanaman utama di sawah. Pemanfaatan limbah pertanian dari pekarangan, rumah tangga ataupun dari kebun sayuran untuk dijadikan kompos ataupun pupuk organik belum dilakukan, hal ini karena terbatasnya informasi. Namun dalam meningkatkan pemanfaatan pekarangan biasanya dengan tanaman selain padi, artinya, belum pernah dengan menanam padi. Karena menurut pendapat para ibu padi hanya bisa ditanam dalam kondisi banyak air dan harus sawah. Pengetahuan bahwa padi adalah tanaman darat dan dalam pertumbuhannya tidak perlu banyak air belum mereka ketahui dan pahami. Kelompok ibu PKK ini secara keseluruhan belum pernah mendengar tentang metode penanaman padi secara SRI, yaitu menanam padi satu biji perlubang dan dalam kondisi macak-macak, pada waktu tertentu air harus kering sekali. Pengetahuan tentang padi metode SRI masih kurang, apalagi padi tersebut ditanam di pot. Introduksi padi hitam Metode SRI di pot sebagai wujud lumbung hidup cukup potensial untuk dikembangkan.

\section{MASALAH}

Permasalahan di desa ini adalah ketergantungan petani pada pupuk anorganik yang tinggi yaitu pupuk lengkap (Urea, SP-36, KCl) sedangkan padi hitam yang ditanam secara SRI budidayanya adalah organik. Berdasarkan penjelasan diatas maka permasalahan kedua mitra adalah:

1. Mitra belum mengetahui cara bertanam padi Hitam secara SRI di pot;

2. Mitra belum pernah menggunakan dan mengetahui cara mengolah limbah pertanian menjadi pupuk organik cair (POC), pupuk padat (kompos) dengan bantuan biodekomposer MOL RINMAS yang tersedia di sekitar rumah dan sawah; dan

3. Mengurangi ketergantungan terhadap bantuan PEMDA/Dinas Pertanian akan pupuk anorganik. 


\section{METODE}

Duaja dkk.

Metode yang digunakan adalah pendidikan kepada masyarakat melalui:

- Ceramah: tentang teknologi MOL URIN (RIN) dan MOL KEONGMAS (MAS) dalam mengolah limbah pertanian, sampah daun/sampah pertanian menjadi pupuk organik cair dan padat menggunakan brosur/leaflet dan infokus di Kantor Desa.

- Mengadakan diskusi dan tanya jawab tentang padi Hitam Metode SRI, alat dan bahan apa yang dibutuhkan (dari materi ceramah dan demonstrasi) yang telah diberikan.

- Demonstrasi cara menanam padi HITAM Metode SRI di pot.

- Demonstrasi tentang cara membuat dan menggunakan alat dan cara mengaplikasikan dalam mengolah limbah pertanian dan sampah rumah tangga menjadi pupuk padat dan pupuk cair dengan MOL Urin dan MOL Keongmas.

- Penerapan pupuk padat dan pupuk cair ke pot padi Hitam Metode SRI di pekarangan.

- Pemantauan secara berkala oleh Tim Pelaksana dilakukan dengan site visit ke lokasi demplot, dua minggu sekali. Untuk Mitra Kelompok PKK dapat dilakukan setiap hari.

Populasi untuk penerapan adalah 25 orang anggota PKK KT Sido Rukun dan 25 orang dari KT Sido Mukti. Pengambilan sampel untuk mengetahui partisipasi petani dilakukan secara purposive random sampling. Data yang dikumpulkan adalah data primer diperoleh dari sampel dengan berpedoman pada kuesioner yang sudah disiapkan. Data yang dikumpulkan adalah data ketika penyuluhan, berapa jumlah anggota yang hadir dan respon terhadap materi yang diberikan. Selanjutnya data ketika demonstrasi plot (jumlah petani yang hadir dan ikut pembuatan MOL, pembibitan secara SRI, penanaman, pemberian pupuk).

\section{HASIL DAN PEMBAHASAN}

\section{Tingkat partisipasi petani dalam penerapan teknologi}

Partisipasi ibu PKK adalah proses ikut serta dalam pengembangan anggota PKK. Partisipasi merupakan unsur pokok pemberdayaan dan merupakan langkah penting memberdayakan masyarakat. Dalam pelaksanaan program partisipasi petani menjadi salah satu faktor yang mempengarui keberhasilan program [7].

\section{Penyuluhan materi teknologi SRI dan MOL RINMAS}

Berdasarkan hasil pendampingan dari dua kelompok PKK, tingkat partisipasi yang tinggi adalah waktu penyuluhan materi teknologi. Penyuluhan materi dilakukan pada sore hari sesuai permintaan dari ibu PKK dan KWT, karena pada sore hari mereka tidak bekerja. Penyuluhan dan demonstrasi dilakukan sebanyak $10 \mathrm{kali}$, dan jumlah kehadiran dirata-ratakan. Secara umum peserta sangat berminat dengan materi yang diberikan karena berhubungan langsung dengan usaha yang mereka lakukan.

Tabel 1. Pelaksanaan kegiatan dan kategori evaluasi penerapan teknologi RINMAS pada padi hitam

\begin{tabular}{llllcl}
\hline No. & \multicolumn{1}{c}{ Nama Kegiatan } & \multicolumn{1}{c}{ Program } & Kategori & $\begin{array}{c}\text { Jumlah } \\
\text { kehadiran }\end{array}$ & $\%$ \\
\hline 1 & Sosialisasi program & Sosialisasi kegiatan ke mitra & Tinggi & 46 & 92 \\
\hline 2 & $\begin{array}{l}\text { Peningkatan } \\
\text { pengetahuan tentang } \\
\text { pemanfaatan } \\
\text { pekarangan }\end{array}$ & $\begin{array}{l}\text { 1. Penyuluhan tentang } \\
\text { tanaman potensial yang } \\
\text { dapat di budidaya di } \\
\text { pekarangan }\end{array}$ & Sedang & 32 & 64 \\
& $\begin{array}{l}\text { 2. Penyuluhan tentang } \\
\text { pengelolaan limbah ternak } \\
\text { dan pertanian menjadi } \\
\text { pupuk organik dengan } \\
\text { dekomposer. }\end{array}$ & Sedang & 36 & 72 \\
& & & & \\
& & & & \\
\end{tabular}




\begin{tabular}{|c|c|c|c|c|c|}
\hline No. & Nama Kegiatan & Program & Kategori & $\begin{array}{c}\text { Jumlah } \\
\text { kehadiran }\end{array}$ & $\%$ \\
\hline & & $\begin{array}{l}\text { 3. Penyuluhan tentang } \\
\text { budidaya padi di pot atau } \\
\text { ember bekas }\end{array}$ & sedang & 38 & 76 \\
\hline \multirow[t]{2}{*}{3} & $\begin{array}{l}\text { Peningkatan } \\
\text { pengetahuan tentang } \\
\text { Teknologi MOL } \\
\text { RINMAS }\end{array}$ & $\begin{array}{l}\text { 1. Demonstrasi cara Membuat } \\
\text { MOL RINMAS (dihasilkan } \\
1001 / \text { kelompok MOL urin } \\
\text { dan } 100 \text { 1/kelompok MOL } \\
\text { keongmas) }\end{array}$ & Tinggi & 45 & 90 \\
\hline & & $\begin{array}{l}\text { 2. Demonstrasi cara membuat } \\
\text { bioinsektisida dari gamal, } \\
\text { mimba dan cabe } \\
\text { (dihasilkan10 liter setiap } \\
\text { MOL) }\end{array}$ & Tinggi & 42 & 84 \\
\hline \multirow[t]{2}{*}{4} & $\begin{array}{l}\text { Peningkatan } \\
\text { pengetahuan tentang } \\
\text { pemanfaatan limbah } \\
\text { ternak menjadi } \\
\text { pupuk organik padat }\end{array}$ & $\begin{array}{l}\text { 1. Penyuluhan tentang } \\
\text { Teknologi Penerapan MOL } \\
\text { RINMAS pada pembuatan } \\
\text { pupuk organik padat dan } \\
\text { cair }\end{array}$ & Tinggi & 47 & 94 \\
\hline & $\begin{array}{l}\text { dan cair dengan } \\
\text { biodekomposer }\end{array}$ & $\begin{array}{l}\text { 2. Demonstrasi membuat. } \\
\text { MOL RINMAS dan } \\
\text { kompos/pupuk padat } \\
\text { (dihasilkan } 100 \mathrm{~kg} \\
\text { kompos/kelompok/bulan) } \\
\text { dan } 100 \text { liter POC. }\end{array}$ & Tinggi & 48 & 96 \\
\hline \multirow[t]{6}{*}{5} & $\begin{array}{l}\text { Menanam padi hitam } \\
\text { di pot }\end{array}$ & $\begin{array}{l}\text { 1. Pengolahan tanah metode } \\
\text { SRI (secara umum) }\end{array}$ & Sedang & 35 & 70 \\
\hline & & $\begin{array}{l}\text { 2. Pesemaian padi secara } \\
\text { konvensional dan SRI }\end{array}$ & Tinggi & 36 & 72 \\
\hline & & $\begin{array}{l}\text { 3. Penanaman padi ( } 100 \\
\text { polibag/kelompok) - ada } \\
10 \text { kelompok }\end{array}$ & Sedang & 38 & 76 \\
\hline & & $\begin{array}{l}\text { 4. Penerapan pupuk padat dan } \\
\text { cair di tanaman padi }\end{array}$ & Tinggi & 40 & 80 \\
\hline & & $\begin{array}{l}\text { 5. Penerapan teknologi } \\
\text { dilakukan sejak tanam dan } \\
\text { diulang pada setiap stadia } \\
\text { pertumbuhan padi }\end{array}$ & & & \\
\hline & & 6. Penyiangan & Rendah & 20 & 40 \\
\hline
\end{tabular}

Sumber: Data Primer Diolah (2017)

\section{Penyuluhan materi teknologi SRI dan MOL RINMAS}

Berdasarkan hasil pendampingan dari dua kelompok PKK, tingkat partisipasi yang tinggi adalah waktu penyuluhan materi teknologi. Penyuluhan materi dilakukan pada sore hari sesuai permintaan dari ibu PKK dan KWT, karena pada sore hari mereka tidak bekerja. Penyuluhan dan demonstrasi dilakukan sebanyak 10 kali, dan jumlah kehadiran dirata-ratakan. Secara 
umum peserta sangat berminat dengan materi yang diberikan karena berhubungan langsung dengan usaha yang mereka lakukan.

\section{Demonstrasi cara Penyiapan benih}

Berdasarkan hasil pendampingan dalam penyiapan benih, tingkat partisipasi sangat rendah yang hadir pada umumnya hanya ibu PKK non KWT. Keadaan ini disebabkan karena KWT (Kelompok Wani Tani) adalah wanita yang kesehariannya adalah buruh tani di persiapan benih, penanaman, pembersihan gulma dan pemupukan. Persiapan benih, pembibitan dan penanaman adalah satu paket kegiatan rutin oleh KWT, sehingga mereka sudah tau dan tidak merasa penting. Hal ini menurut Nurhadi [8], partisipasi tinggi apabila masyarakat merasa informasi baru yang mereka terima akan meningkatkan pengetahuan mereka. Informasi pada tahap ini sebenarnya sangat penting karena berbeda dengan cara konvensional, pada penyiapan benih untuk pembibitan secara SRI, benih direndam menggunakan air garam selanjutnya air kelapa muda, ini merupakan imunisasi bagi benih. Menurut Duaja dkk [4, 5], imunisasi adalah cara pencegahan penyakit padi sejak dini.

\section{Pesemaian}

Berdasarkan hasil pendampingan, tingkat partisipasi ibu PKK pada tahap dikategorikan sedang. Keadaan ini sama dengan pembahasan sebelumnya bahwa pekerjaan ini sudah biasa dilakukan oleh para ibu tani dan KWT. Penyuluhan dan demonstrasi tentang cara pesemaian dengan Metode SRI berbeda dengan cara konvensional, karena pesemaian dilakukan dengan dua cara yaitu cara basah di areal sawah dan cara kering dengan mampan dapat dilakukan di pekarangan rumah. Informasi ini masih terbatas sehingga ibu PKK dapat menginformasikan ke kepala keluarga.

\section{Pengolahan tanah dan pemberian pupuk dasar}

Berdasarkan hasil pendampingan, tingkat partisipasi petani pada tahap ini sangat tinggi. Pengolahan tanah untuk media penanaman padi dilakukan dengan cara konvensional, secara bersama-sama menjadi lebih cepat. Pemberian pupuk padat berbasis MOL RINMAS yang merupakan pupuk dasar diberikan pada tahap ini, adalah tahap awal aplikasi teknologi RINMAS. Partisipasi sangat tinggi karena anggota sudah mengerti arti pupuk organik. Berdasarkan wawancara terhadap anggota PKK, lima puluh persen anggota PKK sudah mengetahui cara memanfaatkan jerami padi untuk menaikkan $\mathrm{pH}$. Beberapa anggota PKK sudah menggunakan kotoran sapi untuk pupuk dasar dan sudah diterapkan tetapi kotoran sapi tersebut tidak difermentasi terlebih dahulu hanya di biarkan di kandang dan di sekitar kebun selama 3 bulan baru digunakan.

\section{Penanaman padi secara SRI}

Berdasarkan hasil pendampingan tingkat partisipasi pada tahap ini termasuk sedang. Artinya penanaman padi secara SRI sudah diketahui ibu PKK karena sebagian besar anggota adalah juga ibu KWT, merupakan buruh tani yang biasa diupah dalam pembibitan, penanaman dan penyiangan. Metode SRI, dapat mengurangi penggunaan benih per hektar [6], namun metode ini terasa sulit untuk anggota PKK yang bukan merupakan anggota KWT, karena bibit ditanam muda dan hanya 1-3 batang perumpun, bibit sangat sensitif terutama di makan oleh hama keong mas dan orong-orong.

\section{Teknologi MOL RINMAS}

Berdasarkan hasil pendampingan, tingkat partisipasi tinggi pada pembuatan MOL Keong Mas, porasi padat, MOL Urin dan pupuk organik cair. Tingkat partisipasi yang tinggi pada MOL Keong Mas karena pada dasarnya anggota PKK belum pernah membuat sehingga ini merupakan informasi yang baru. Selain hal tersebut karena keong mas merupakan hama utama pada tanaman padi. Demikian juga pada MOL Urin, partisipasi anggota PKK tinggi karena pengetahuan mereka hanya pada kotoran sapi, urin sapi hanya terbuang saja. Pada pembuatan MOL Urin anggota PKK juga meminta di dampingi (kepala keluarga) untuk mempersiapkan kandang agar urin dapat disalurkan langsung ke tempat penampungan di kandang sapi mereka. 
Ini merupakan respon yang dikuti dengan keberlanjutan. Mitra merasa adanya kesesuain teknologi dengan keberadaan keluarga petani meningkatan akseptabilitas teknologi [3].

Partisipasi anggota PKK juga tinggi pada pembuatan Porasi Padat. Bahan utama porasi padat adalah kotoran sapi, ayam dan kambing. Dengan teknologi MOL RINMAS bahan dekomposer tidak perlu dibeli. Ini merupakan informasi baru bagi ibu PKK. Penerapan MOL RINMAS pada tanaman kedelai di pekarangan merupakan informasi bagi keluarga petani yang lain (learning by doing). Partisipasi anggota KWT menjadi motivasi anggota kelompok tani. Walaupun tingkat partisipasi ada yang sedang sampai tinggi tapi ini sudah merupakan awal dari akseptibilitas teknologi [1].

\section{Penyiangan}

Indikator penyiangan termasuk rendah disebabkan anggota PKK tidak merasa perlu untuk melakukan penyiangan, karena padi ditanam di pot gulma sedikit, namun informasi perlu di sampaikan karena mereka juga menanam kacang-kacangan di lahan sawah. Menurut ibu PKK, banyaknya keongmas di lahan sawah mempengaruhi pertanaman di musim tanam berikutnya. Keongmas akan memusnahkan gulma yang baru tumbuh, sehingga petani tidak melakukan penyiangan. Keaadaan serupa juga ditemukan pada penelitian Fitri dan Dedy [6], petani pada umumnya merasa tidak perlu melakukan pembersihan gulma karena gulma pada umumnya dimakan oleh keongmas.

\section{KESIMPULAN}

Tujuan pemberdayaan masyarakat melalui desiminasi teknologi pada tanaman padi hitam cukup baik dilihat dari tingkat partisipasi kelompok PKK. Kegiatan pengabdian ini meningkatkan hasil pekarangan dengan adanya padi hitam. Potensi pekarangan untuk meningkatkan ekonomi khususnya diperdesaan sangat baik, terutama dengan memanfaatkan limbah tanaman dan ternak dan tanaman yang pontensi sebagai insektisida hayati.

\section{UCAPAN TERIMA KASIH}

Ucapan terima kasih kepada:

1. Kementerian Riset, Teknologi dan Pendidikan Tinggi atas Hibah Pengabdian pada Masyarakat Skim Ipteks bagi Masyarakat.

2. Fakultas Pertanian Universitas Jambi, atas bantuan penggunaan alat-alat

3. LPPM Universitas Jambi atas fasilitas yang diberikan selama kegiatan berlangsung.

4. Seluruh Penyuluh Pertanian Lapangan (PPL) kecamatan Batang Asam dan aparat Desa Sri Agung.

\section{Daftar Pustaka}

1. Amar, K.Z., dan N. Tjetjep. 2013. Strategi Penggalangan Petani Untuk Mendukung Program Peningkatan Produksi Padi Berkelanjutan. Analisis Kebijakan Pertanian 11(2): 75-87.

2. BPS. 2016. BPS Kabupaten Tanjung Jabung Barat. Kuala Baru, Tungkal Ilir.

3. Budianto, J. 1999. Akseptabilitas Teknologi Pertanian Bagi Konsumen. Dalam Tonggak Kemajuan Teknologi Produksi Tanaman Pangan, Konsep dan Strategi Peningkatan Produksi Pangan. Simposium Penelitian Tanaman Pangan IV. Puslitbang Tanaman Pangan. Badan Litbang Pertanian: 12-23.

4. Duaja, M.D., Buhaira, dan Muksin. 2016. Peningkatan Produksi Padi Dengan Diseminasi Teknologi Sri Organik Berbasis Mixmol Melalui Pemberdayaan Masyarakat KKN-PPM. Prosiding Konferensi Nasional PKMCSR 2. Padang.

5. Duaja, M.D., Johannes, dan Buhaira. 2017. Pemberdayaan Masyarakat Dalam Mengolah Limbah Menjadi Pupuk dan Insektisida dan Penerapannya Pada Tanaman Padi. Prosiding Konferensi Nasional PKMCSR 3. Solo. 
6. Fitri dan K. Dedy. 2014. Partisipasi Anggota Kelompok Tani dalam Penerapan Teknologi Tanam Sebatang di Desa Taratak Bancah Kecamatan Silungkang Kota Sawah Lunto. Jurnal Penyuluhan Pertanian 9(1).

7. Lugiarti, E. 2004. Peningkatan Partisipasi Masyarakat dalam Proses Perencanaan Program Pengembangan Masyarakat di Komunitas Desa Cijayanti. Tesis, Institut Pertanian Bogor.

Duaja dkk.

Nurhadi, A. 2017. Hubungan Antara Persepsi dan Keragaman Motif Sosial dengan Tingkat Partisipasi Masyarakat dalam Program CSR PT. X (Kasus Koperasi Serba Usaha Rancage CSR (Kasus Koperasi Serba Usaha Rancage). Tesis, Institut Pertanian Bogor. 